\title{
Physical activity and quality of life in long- term hospitalized patients with severe mental illness: a cross-sectional study
}

Jeroen Deenik ${ }^{1,2,3^{*}}$ (D), Frank Kruisdijk ${ }^{1,4}$, Diederik Tenback ${ }^{1,5}$, Annemarie Braakman-Jansen², Erik Taal ${ }^{2}$, Marijke Hopman-Rock ${ }^{4,6,7}$, Aartjan Beekman ${ }^{8}$, Erwin Tak ${ }^{4,6}$, Ingrid Hendriksen ${ }^{4,6}$ and Peter van Harten ${ }^{1,3}$

\begin{abstract}
Background: Increasing physical activity in patients with severe mental illness is believed to have positive effects on physical health, psychiatric symptoms and as well quality of life. Till now, little is known about the relationship between physical activity and quality of life in long-term hospitalized patients with severe mental illness and knowledge of the determinants of behavioural change is lacking. The purpose of this study was to elucidate the relationship between objectively measured physical activity and quality of life, and explore modifiable psychological determinants of change in physical activity in long-term hospitalized patients with severe mental illness.

Methods: In 184 inpatients, physical activity was measured using an accelerometer (ActiGraph GTX+). Quality of life was assessed by EuroQol-5D and WHOQol-Bref. Attitude and perceived self-efficacy towards physical activity were collected using the Physical Activity Enjoyment Scale and the Multidimensional Self Efficacy Questionnaire, respectively. Patient and disease characteristics were derived retrospectively from electronic patient records. Associations and potential predictors were analysed using hierarchical regression.

Results: Physical activity was positively related with and a predictor of all quality of life outcomes except on the environmental domain, independent of patient and disease characteristics. However, non-linear relationships showed that most improvement in quality of life lies in the change from sedentary to light activity. Attitude and self-efficacy were not related to physical activity.

Conclusions: Physical activity is positively associated with quality of life, especially for patients in the lower spectrum of physical activity. An association between attitude and self-efficacy and physical activity was absent. Therefore, results suggest the need of alternative, more integrated and (peer-)supported interventions to structurally improve physical activity in this inpatient population. Slight changes from sedentary behaviour to physical activity may be enough to improve quality of life.
\end{abstract}

Keywords: Schizophrenia, Physical activity, Accelerometry, Inpatients, Quality of life, Attitude; self-efficacy

\section{Background}

Research into lifestyle-related factors in patients with Severe Mental Illness (SMI) is increasing. Efforts often focus on physical health, consistent with the highly prevalent metabolic risk factors [1] that underlie the well-known poor cardiovascular health and premature

\footnotetext{
* Correspondence: j.deenik@ggzcentraal.nl

${ }^{1}$ GGz Centraal, Utrechtseweg 266, 3818 EW Amersfoort, The Netherlands

${ }^{2}$ Faculty of Behavioural, Management and Social sciences, University of

Twente, Drienerlolaan 5, 7522 NB Enschede, The Netherlands

Full list of author information is available at the end of the article
}

mortality gap of at least 10-20 years compared to the general population [2, 3]. Recent systematic reviews and meta-analyses showed beneficial effects of increasing physical activity (PA) on physical health, psychiatric symptoms, global functioning, and quality of life (QoL) [4-7]. These are relevant findings, especially for longterm hospitalized patients with SMI, given the combination of a strong negative relationship between illness duration and QoL [8] and a high level of sedentariness in this population [9]. 
Although QoL is a complex construct influenced by multiple factors [10], these recent findings positively support PA as an important modifiable factor affecting patients' QoL.

However, until now little is known about the relationship between objective measured PA and QoL in longterm hospitalized patients with SMI and most of the studies in the referred systematic reviews and metaanalyses involved outpatient- or short term hospitalized populations. Objective PA measurement of patients with long-term hospitalization due to their illness severity remains a challenge and just a few studies succeeded in such measurements at larger scale $[9,11,12]$.

Also, despite growing awareness of the positive effects of increasing PA in patients with SMI, no clear answer exists on how to motivate patients with SMI to structurally engage in PA [13]. In addition, the hospital setting has been considered 'obesogenic' and a cause of inactivity itself $[14,15]$. A long term stay therefore negatively affects PA due to regulated inactivity. More knowledge of determinants of change in PA in this population is needed. The Theory of Planned Behaviour [16], a basic social-cognitive model, provides insight into such determinants. It distinguishes attitudes towards the desired behaviour and its outcomes, subjective norms (perceived social pressure and (dis)approval of certain behaviours) and perceived behavioural control [16], also defined as self-efficacy [17]. These determinants are assumed to affect one's intention to perform the given behaviour, which is hypothesized to be the immediate antecedent of the actual behaviour (e.g. being more physically active). Especially in long-term mental healthcare, it is important to gain more insight into psychiatric and psychological determinants of PA to guide activation [18]. However, in SMI patients the abovementioned subjective norms and the ability to consciously establish intentions towards behaviour are affected by a lack of insight into their condition, poor skills in cognitive empathy and planning deficits [19-21]. Therefore, we decided to explore attitude and self-efficacy as determinants with the greatest potential to influence the result of treatment. To our knowledge, these determinants are rarely studied in a SMI population and have never been associated with objectively measured PA.

The aim of our study was to (A) analyse the relationship between objectively measured PA and QoL in longterm hospitalized patients with severe mental illness and (B) explore to what extent attitude and self-efficacy are related to the level of PA in this population.

\section{Methods}

\section{Participants}

Subjects were long-term hospitalized patients with SMI of a psychiatric hospital in The Netherlands for whom we provide mental healthcare and residence if they are unable to live independently or in sheltered homes. Inclusion criteria were age $\geq 18$, hospitalized $\geq 1$ year and treatment history $\geq 2$ years. For the current study, we used accelerometer data previously reported by Kruisdijk et al. [9]. In this relevant study, forty-four patients were excluded because of no informed consent $(n=26)$, unstable psychiatric or physical conditions $(n=17)$ or relocation $(n=1)$. Of the 207 included patients, 23 dropped out because of a lack of required wear time $(n=19)$, losing their accelerometer $(n=2)$, discharge during the study period $(n=1)$ or an acute episode of illness $(n=1)$. In total 184 patients were included with sufficient accelerometer data, that we used in analysis in the current study, which was approved by the Central Committee on Research Involving Human Subjects (CCMO). After extensive verbal explanation per ward, taking understandable comments due to the mental illness into account (e.g. fear, suspicion and psychotic thoughts), written informed consent was obtained from all subjects who understood the intent of the study and were willing to participate.

\section{Procedures}

To measure PA, subjects wore an accelerometer (ActiGraph GT3X+) for five consecutive days (Wednesday morning to Sunday evening) except while sleeping or during water related activities [9]. Questionnaires for QoL and attitude and self-efficacy as determinants of change in PA were added to the routine health screening and conducted by a trained research assistant in a semistructured interview. The average duration of a screening was $20-30 \mathrm{~min}$, depending on the specific patient. If needed, the screening was split up into two appointments (e.g. due to a limited attention span).

\section{Measurements \\ Patient- and disease-specific characteristics}

Gender, age, years of hospitalization, diagnosis, illness severity and use of medication were derived retrospectively from electronic patient records. Primary diagnoses were classified following the DSM-IV-TR in main groups of the most frequent diagnoses: schizophrenia and other psychotic disorders, personality disorders and affective disorders. Less frequent diagnoses were merged in 'others'. Furthermore, affective disorders were split into depression and bipolar disorder. Use of antipsychotics was split into first, second or both generations, because the difference in side-effects (movement disorders and metabolic sideeffects, respectively) may have an effect on the activity level. Severity of illness was measured by the Dutch translation of the severity-scale of the Clinical Global Impression Scale (CGI, [22]), rating from 1 (normal, not at all ill) to 7 (among the most extremely ill patients). 


\section{Physical activity}

The ActiGraph GT3X+ (ActiGraph, Pensacola, Florida, VS) was used to measure PA. The accelerometers were worn on the right hip with an elastic strap between two belt loops. Patients without belt loops used a pouch pinned at the same place. A wear time of $\geq 6 \mathrm{~h} /$ day for $\geq 3$ days was used as the criterion for sufficient measurement. To be able to compare individual data, the same timeframe was used for each dataset: 09.00 am till $10.00 \mathrm{pm}$. Data were analysed using the ActiGraph software ActiLife 6.8.0 and calculated into average total activity counts per hour $(\mathrm{TAC} / \mathrm{h})$ as a continuous and detailed outcome variable of PA, where more counts indicate a higher level of PA. For detailed information on used settings and criteria, see Kruisdijk et al. [9]. The GT3X+ has a high inter- and intra-instrumental reliability and validity [23-25].

\section{Quality of life}

The Dutch versions of the EuroQol 5D (EQ-5D) and brief World Health Organization Quality of Life Assessment scale (WHOQoL-Bref) were used to assess QoL. As a generic instrument, the EQ-5D measures five dimensions of health (one item each): mobility, self-care, usual activities, pain/discomfort and anxiety/depression, rated from 1 (no problems) to 3 (many problems). The added value of the EQ-5D is the calculation of an index score ranging from 0 (worst QoL) to 1 (perfect QoL) using the Dutch value-set based on time-trade-off weightings of a representative Dutch sample [26]. The EQ-5D is a valid instrument to measure QoL in patients with a diagnosis of schizophrenia [27].

Because the EQ-5D is recommended to be used complementary to other instruments [28] and physical disability and poor daily functioning not necessarily mean that the particular patient has a poor QoL [29], we added the WHOQoL-Bref. This questionnaire focuses on ones' perceived QoL, including 24 items divided in four domains: physical (7 items), psychological (6 items), social (3 items) and environmental (8 items). In addition, there are two items that individually score one's overall perception of QoL and satisfaction with his/her health. Items are scored on a five-point Likert scale (1 to 5; e.g. from 'very dissatisfied' to 'very satisfied'). Scores were transformed into domain scores ranging from 4 to 20 , according to the WHO guidelines. The WHOQoL-Bref is the most often used QoL-instrument in studies investigating patients with a diagnosis of schizophrenia [30] and showed good to excellent reliability and validity in these patients in long-term mental healthcare [31] and in Dutch outpatients with psychiatric disorders [32]. In the present study, we found a sufficient internal consistency in the separate domains: physical $(\alpha=0.74)$, psychological $(\alpha=0.82)$, social $(\alpha=0.63)$ and environmental $(\alpha=0.72)$.

\section{Attitude \& self-efficacy towards physical activity}

For these measures, no validated Dutch questionnaires were available for this population. Therefore, attitude was measured using the Dutch version of the Physical Activity Enjoyment Scale (PACES; [33]), previously used in the general population [34]. It includes 18 dichotomous statements regarding the participants' thoughts about physical activities they do (or used to do). Items are scored at a Likert-scale from 1 to 7 whereby participants choose the number that most closely corresponds to the way they feel (e.g. 'I feel bored' vs. 'I feel interested'). Eleven items are formulated negatively. After recoding these items, a sumscore was calculated, with a higher score representing a more positive attitude towards PA (range 18-126). In the present study, the questionnaire showed a high internal consistency $(\alpha=.97)$.

Self-efficacy was measured with a questionnaire based on the Multidimensional Self Efficacy Questionnaire (MSEQ; [35]). Originally, this questionnaire comprised 18 items measuring the extent to which a patient feels able to be physically active (e.g. 'I am confident in my ability to exercise when I am under a lot of stress'). Items are scored on a Likert-scale from 1 (totally unable) to 5 (totally able). For use in the present study, the questionnaire was translated (once forwards) into Dutch. To avoid unduly burdening patients with irrelevant questions and to have a questionnaire in line with the treatment conditions, some adjustments were made. First, using understandable terminology towards patients, we replaced the word 'exercise' by 'be physically active'. Secondly, due to the inpatient setting, the item regarding PA when traveling became unnecessary and was deleted, and items referring to several social situations were reduced to one item focusing on the situation at the treatment group (I am confident in my ability to be in PA when my fellow group members don't want me to go to physical activities). Finally, one of the three items regarding cold weather conditions was adjusted into an item on hot weather, in order to involve summer conditions. A sum score was used with a higher score representing a higher self-efficacy towards PA (range 15-75). In the present study, the adjusted questionnaire showed a high internal consistency $(\alpha=0.92)$.

\section{Statistical analysis}

Data analyses were performed using SPSS 22.0. Continuous variables were examined for normality and homogeneity by comparing means with medians and standard deviations, and by analysing frequency histograms and normality plots. Linearity was examined by scatterplots and analysing the variables in quartiles. If variables were not distributed linearly with respect to the dependent variables, they were added as quartiles in the analysis, with the first quartile as reference-category. Categorical 
variables (diagnosis and types of antipsychotics) were transformed into dummy variables. 'Schizophrenia and other psychotic disorders' and 'first generation antipsychotics' were the reference groups for diagnosis and antipsychotics, respectively.

Relationships between the independent (PA, attitude or self-efficacy) and dependent variable (QoL outcomes or PA) were analysed using linear regression. First, analyses focused on these associations specifically. To estimate these associations as accurately as possible, it was checked whether patient and disease characteristics affected the relationship. This confounding was defined as a change of $\geq 10 \%$ in the regression coefficient of the particular independent variable (e.g. PA) when adding a patient or disease characteristic. The strongest confounder was added to the model to control for, until there were no variables left causing $\geq 10 \%$ change in the regression coefficient. For the analysis of PA, we also controlled for the way of attachment of the accelerometer. Associations were considered significant at a 0.05 two tailed significance level. Then, regardless of any specific association, significant predictors of QoL and PA were analysed using multiple regression with manual backward elimination retaining only the strongest predictors $(p<0.10)$. Proportions of explained variance were reported to give an indication of the predictive power of these models. Multicollinearity was examined by observing regression coefficients (e.g. change of direction when adding variables) and collinearity statistics (VIF $>10$ and tolerance $<0.2$ ). Because PA is represented in large numbers by total activity counts per hour, the variable was standardized (each value subtracted by the mean total activity counts per hour and divided by its $\mathrm{SD})$ to use as independent variable in analysis towards QoL, in order to optimize readability.

\section{Results}

Table 1 shows the characteristics of the 184 participants. They were between 25 and 91 years old and hospitalized with a minimum of one and a maximum of 58 years.

\section{Physical activity and quality of life}

When examining scatterplots, we found that PA was nonlinearly distributed towards QoL. Although there was no obvious alternative shape of the distribution (e.g. quadratic), smoothing a line using Locally Estimated Scatterplot Smoothing (LOESS) [36] clearly visualized that QoL did not constantly increase with more PA (Fig. 1). Coefficients of PA quartiles confirmed this finding (Table 3). Because of this non-linearity, quartiles were used in the regression analysis, with the lowest quartile (Q1) as reference group. To support interpretation of the results, Table 2 provides insight into means of activity counts and corresponding intensities
Table 1 Patient and disease characteristics, physical activity, quality of life, attitude and self-efficacy ( $N=184)$

\begin{tabular}{|c|c|c|c|c|}
\hline \multirow{2}{*}{$\begin{array}{l}\text { Variable (scale) } \\
\text { Gender (men) }\end{array}$} & \multicolumn{2}{|l|}{ Mean (SD) } & \multicolumn{2}{|c|}{ N (\%) } \\
\hline & & & 108 & $(58.7)$ \\
\hline Age (years) & 57.4 & $(12.8)$ & & \\
\hline \multicolumn{5}{|l|}{ Diagnosis } \\
\hline $\begin{array}{l}\text { Schizophrenia and } \\
\text { other psychotic } \\
\text { disorders }\end{array}$ & & & 142 & $(77.2)$ \\
\hline Personality disorder & & & 17 & $(9.2)$ \\
\hline \multicolumn{5}{|l|}{ Mood disorder } \\
\hline Depressive & & & 6 & (3.3) \\
\hline Bipolar & & & 7 & (3.8) \\
\hline Others $^{a}$ & & & 12 & $(6.5)$ \\
\hline $\begin{array}{l}\text { Years of hospitalization, } \\
\text { median } \\
\left(25-75 \text { percentile) }{ }^{b}\right.\end{array}$ & 6.0 & $(4.0-21.8)$ & & \\
\hline $\begin{array}{l}\text { Severity of illness } \\
\text { (range 1-6) }\end{array}$ & 4.7 & (1.4) & & \\
\hline \multicolumn{5}{|l|}{ Medication } \\
\hline \multicolumn{5}{|l|}{ Antipsychotics } \\
\hline First generation & & & 36 & (19.6) \\
\hline Second generation & & & 70 & (38.0) \\
\hline Both & & & 73 & (39.7) \\
\hline Antidepressants & & & 82 & $(44.6)$ \\
\hline $\mathrm{TAC} / \mathrm{h}$ & 24,527 & $(14821)$ & & \\
\hline $\begin{array}{l}\text { EQ-5D index } \\
\text { score }(0-1)\end{array}$ & 0.6 & $(0.3)$ & & \\
\hline \multicolumn{5}{|l|}{ WHOQoL-Bref } \\
\hline $\begin{array}{l}\text { Overall QoL } \\
\text { rating }(1-5)\end{array}$ & 3.5 & $(0.9)$ & & \\
\hline $\begin{array}{l}\text { Health satisfaction } \\
\text { rating (1-5) }\end{array}$ & 3.4 & $(1.1)$ & & \\
\hline $\begin{array}{l}\text { Physical domain } \\
(4-20)\end{array}$ & 13.6 & $(2.7)$ & & \\
\hline $\begin{array}{l}\text { Psychological } \\
\text { domain (4-20) }\end{array}$ & 13.1 & (3.1) & & \\
\hline $\begin{array}{l}\text { Social domain } \\
(4-20)\end{array}$ & 13.1 & $(2.9)$ & & \\
\hline $\begin{array}{l}\text { Environmental } \\
\text { domain (4-20) }\end{array}$ & 14.9 & $(2.1)$ & & \\
\hline $\begin{array}{l}\text { Attitude towards } \\
\text { PA (18-126) }\end{array}$ & 76.6 & $(26.8)$ & & \\
\hline $\begin{array}{l}\text { Self-efficacy towards } \\
\text { PA (15-75) }\end{array}$ & 41.2 & $(14.6)$ & & \\
\hline
\end{tabular}

TAC/ $h$ average Total Activity Counts per hour, QoL Quality of life, EQ-5D EuroQol five-dimension questionnaire, WHOQoL-Bref World Health Organization Quality of Life questionnaire, brief version

aDelirium, dementia, and amnestic and other cognitive disorders $(n=3)$; substance-related disorders $(n=3)$, somatoform disorders $(n=2)$; mental disorder not otherwise specified $(n=2)$; anxiety disorder $(n=1)$; developmental disorder $(n=1)$

${ }^{\mathrm{b}}$ Positively skewed distribution 


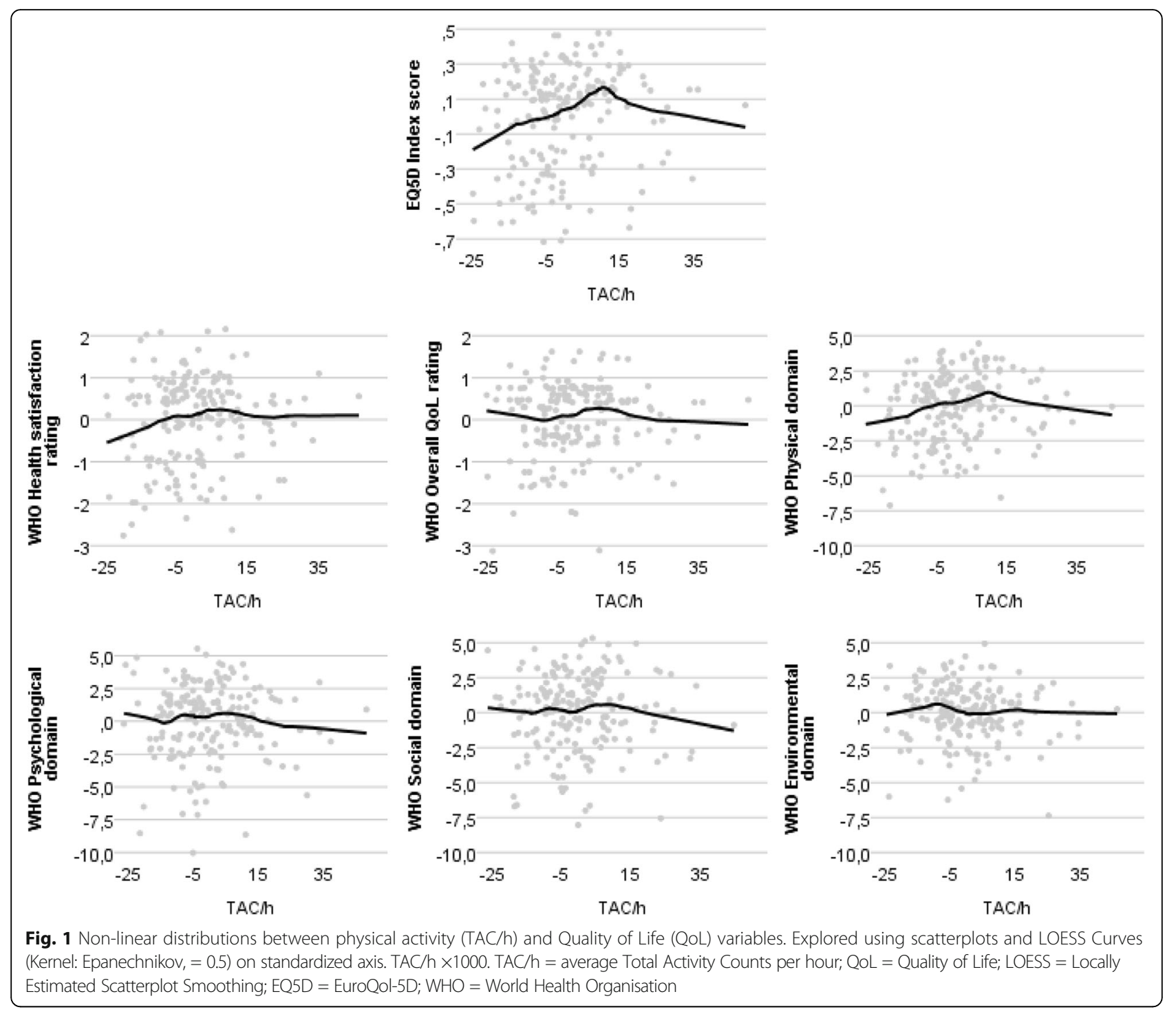

Table 2 Average total activity counts per hour and proportions of wear time in intensities within quartiles

\begin{tabular}{|c|c|c|c|c|c|c|c|}
\hline \multirow[t]{2}{*}{ Quartile } & \multicolumn{4}{|l|}{$\mathrm{TAC} / \mathrm{h}$} & \multicolumn{3}{|c|}{ Intensities ${ }^{c}$} \\
\hline & \multicolumn{2}{|c|}{ Mean (SD) } & \multirow{2}{*}{$\frac{\min ^{b}}{2518}$} & \multirow{2}{*}{$\frac{\max ^{b}}{12,840}$} & \multirow{2}{*}{$\begin{array}{l}\% \mathrm{SB} \\
92.2\end{array}$} & \multirow{2}{*}{$\begin{array}{l}\% \text { LPA } \\
6.2\end{array}$} & \multirow{2}{*}{$\begin{array}{l}\% \text { MVPA } \\
1.6\end{array}$} \\
\hline$\overline{\mathrm{Q} 1^{\mathrm{a}}}$ & 8260 & (2938) & & & & & \\
\hline Q2 & 18,136 & (2973) & 13,350 & 22,317 & 86.0 & 10.1 & 3.9 \\
\hline Q3 & 27,160 & (2663) & 22,566 & 31,469 & 81.9 & 11.7 & 6.4 \\
\hline Q4 & 44,553 & (11814) & 31,702 & 83,698 & 74.4 & 14.0 & 11.6 \\
\hline
\end{tabular}

Q Quartile $(n=46), T A C / h$ average Total Activity Counts per hour, SB Sedentary Behaviour, LPA Light Physical Activity, MVPA Moderate to Vigorous Physical Activity

a reference group in analysis

${ }^{b}$ minimum and maximum average $T A C / h$ (patient) within the quartile

'mean percentage of wear time that patients within the quartile spend in: SB [ $<150$ ], LPA [151-3207], MVPA [ $\geq 3208$; but $\geq 2751$ for 65 years or older] [37-39].

Thresholds in counts per minute within the quartiles, according to age-specific cut-off points for tri-axial measurement [37-39].

Table 3 shows the associations between PA (total activity counts per hour) and QoL with the corresponding confounders, reflected in regression coefficients for the particular associations and $F$-values for the models as a whole. There were significant positive associations between PA and the EQ-5D index score and WHO overall, physical, psychological and social QoL. For overall QoL and the psychological and social domains, patients with PA levels in the lower spectrum $(\mathrm{Q} 2)$ had the best QoL and the QoL of the most active patients (Q4) differed less from the least active patients (Q1, reference group). This corresponds to the shapes of distribution in the uncorrected data, showing a (small) increase which then runs off. There were no significant associations with health satisfaction and environmental QoL. 
Table 3 Associations between outcomes, uncorrected and corrected for confounding patient and disease characteristics

\begin{tabular}{|c|c|c|c|c|c|c|c|c|c|c|c|c|c|}
\hline \multirow[b]{2}{*}{ Variable } & \multicolumn{7}{|c|}{ Corrected for } & \multicolumn{3}{|c|}{ Uncorrected } & \multicolumn{3}{|c|}{ Corrected } \\
\hline & $\underline{A}$ & $\underline{B}$ & $\underline{C}$ & $\underline{\mathrm{D}}$ & $\underline{E}$ & $\underline{F}$ & $\underline{G}$ & B & $(95 \% \mathrm{Cl})$ & $F$ & $\mathrm{~B}$ & $(95 \% \mathrm{Cl})$ & $F$ \\
\hline \multicolumn{14}{|c|}{ Associations between physical activity (TAC/h) and QoL } \\
\hline EQ-5D index score & & $\underline{B}$ & & $\underline{\mathrm{D}}$ & & & & & & $3.89^{*}$ & & & $4.81^{* * *}$ \\
\hline Q2 & & & & & & & & $0.16^{*}$ & $(0.03-0.28)$ & & $0.18 * *$ & $(0.06-0.31)$ & \\
\hline Q3 & & & & & & & & $0.14^{*}$ & $(0.01-0.26)$ & & $0.18^{* *}$ & $(0.05-0.31)$ & \\
\hline Q4 & & & & & & & & $0.20^{* *}$ & $(0.08-0.33)$ & & $0.19 * *$ & $(0.05-0.33)$ & \\
\hline \multicolumn{14}{|l|}{ WHOQoL-Bref } \\
\hline Overall QoL rating & & $\underline{B}$ & & $\underline{\mathrm{D}}$ & & & & & & $2.78^{*}$ & & & $3.20^{* *}$ \\
\hline Q2 & & & & & & & & $0.54^{* *}$ & $(0.17-0.92)$ & & $0.60^{* *}$ & $(0.21-0.98)$ & \\
\hline Q3 & & & & & & & & 0.30 & $(-0.07-0.68)$ & & $0.40 *$ & $(<0.01-0.81)$ & \\
\hline Q4 & & & & & & & & 0.33 & $(-0.05-0.70)$ & & 0.35 & $(-0.08-0.78)$ & \\
\hline Health satisfaction rating & & $\underline{B}$ & $\underline{c}$ & $\underline{\mathrm{D}}$ & & & & & & 1.04 & & & $2.62^{* *}$ \\
\hline Q2 & & & & & & & & 0.39 & $(-0.07-0.85)$ & & 0.47 & $(-0.01-0.94)$ & \\
\hline Q3 & & & & & & & & 0.26 & $(-0.20-0.72)$ & & 0.44 & $(-0.05-0.93)$ & \\
\hline Q4 & & & & & & & & 0.30 & $(-0.16-0.77)$ & & 0.50 & $(-0.03-1.02)$ & \\
\hline Physical domain & $\underline{A}$ & $\underline{B}$ & $\underline{c}$ & $\underline{D}$ & & & & & & $2.75^{*}$ & & & $3.72^{* * *}$ \\
\hline Q2 & & & & & & & & 1.06 & $(-0.02-2.13)$ & & $1.18^{*}$ & $(0.10-2.26)$ & \\
\hline Q3 & & & & & & & & $1.18^{*}$ & $(0.10-2.26)$ & & $1.66^{* *}$ & $(0.54-2.79)$ & \\
\hline Q4 & & & & & & & & $1.47^{* *}$ & $(0.39-2.54)$ & & $1.50 *$ & $(0.31-2.69)$ & \\
\hline Psychological domain & $\underline{A}$ & $\underline{B}$ & & $\underline{D}$ & & & $\underline{G}$ & & & 0.90 & & & $5.22^{* * *}$ \\
\hline Q2 & & & & & & & & 0.88 & $(-0.39-2.15)$ & & $1.35^{*}$ & $(0.11-2.59)$ & \\
\hline Q3 & & & & & & & & 0.45 & $(-0.82-1.72)$ & & 1.01 & $(-0.29-2.31)$ & \\
\hline Q4 & & & & & & & & -0.03 & $(-1.30-1.24)$ & & 0.45 & $(-0.93-1.83)$ & \\
\hline Social domain & & $\underline{B}$ & $\underline{c}$ & & & & & & & 2.06 & & & $2.06^{*}$ \\
\hline Q2 & & & & & & & & $1.42^{*}$ & $(0.23-2.62)$ & & $1.46^{*}$ & $(0.19-2.73)$ & \\
\hline Q3 & & & & & & & & 1.13 & $(-0.07-2.33)$ & & $1.38^{*}$ & $(0.07-2.69)$ & \\
\hline Q4 & & & & & & & & 0.75 & $(-0.44-1.95)$ & & 1.27 & $(-0.12-2.67)$ & \\
\hline Environmental domain & $\underline{A}$ & $\underline{B}$ & $\underline{C}$ & $\underline{\mathrm{D}}$ & $\underline{E}$ & $\underline{F}$ & & & & 0.18 & & & 1.37 \\
\hline Q2 & & & & & & & & 0.23 & $(-0.66-1.12)$ & & 0.04 & $(-0.92-0.99)$ & \\
\hline Q3 & & & & & & & & 0.29 & $(-0.60-1.18)$ & & 0.21 & $(-0.78-1.19)$ & \\
\hline Q4 & & & & & & & & 0.08 & $-0.81-0.97)$ & & -0.16 & $(-1.20-0.89)$ & \\
\hline
\end{tabular}

Associations between attitude and self-efficacy and physical activity (TAC/h)

\begin{tabular}{|c|c|c|c|c|c|c|c|c|}
\hline Attitude towards PA & $\underline{B}$ & $\underline{D}$ & $83.60^{*}$ & $(3.58-163.62)$ & $4.25^{*}$ & 36.54 & $(-34.91-107.99)$ & $14.09 * * *$ \\
\hline Self-efficacy towards PA & $\underline{B}$ & $\underline{C}$ & 82.52 & $(-64.98-230.01)$ & 1.22 & 67.39 & $(-59.69-194.48)$ & $11.24^{* * *}$ \\
\hline
\end{tabular}

Significant results shown in bold. $\underline{A}$, gender; $\underline{B}$, age; $\underline{C}$, diagnosis; $\underline{D}$, illness severity; $\underline{E}$, years of hospitalization; $\underline{F}$, use of antipsychotics; $\underline{G}$, use of antidepressants. $B=$ regression coefficient; $Q=$ Quartile $(n=\overline{4} 6) ; \mathrm{TAC} / \mathrm{h}=$ average Total Activity Counts per hour ${ }^{*} p<0.05$. ${ }^{* *} p<0.01$. ${ }^{* *} p<0.001$

aalso corrected for the way of accelerometer-attachment

The multiple regression with backward elimination showed PA to be a significant predictor for the EQ-5D, WHO overall QoL, health satisfaction and the physical, psychological and social domains (Table 4). Regression coefficients for the prediction of the WHO overall, psychological and social QoL showed the strongest relationships for the lower spectrum of activity (Q2).
This confirmed the distributions we found earlier (Fig. 1). Explained variance $\left(R_{A d j}^{2}\right)$ of the models of these significant predictors ranged between $8 \%$ and $17 \%$. The level of PA was no significant predictor for environmental QoL, which was predicted by years of hospitalization, illness severity and use of antipsychotics $(F=3.91, p<0.01$, $\left.R_{A d j}^{2}=0.06\right)$. 
Table 4 Multiple regression models with significant predictors of quality of life $(p<0.10)$, using backward-selection

\begin{tabular}{|c|c|c|c|c|c|}
\hline Measure & $\mathrm{B}$ & $95 \% \mathrm{Cl}$ & $F$ & $R^{2}$ & $R_{\text {Adj }}^{2}$ \\
\hline \multicolumn{6}{|c|}{ Predicting EQ-5D index score } \\
\hline 2003Overall model & & & $6.76^{* * * *}$ & 0.16 & 0.14 \\
\hline \multicolumn{6}{|l|}{$\mathrm{TAC} / \mathrm{h}$} \\
\hline Q2 & $0.16^{* * *}$ & $(0.05-0.28)$ & & & \\
\hline Q3 & $0.15^{* *}$ & $(0.04-0.27)$ & & & \\
\hline Q4 & $0.17^{* * *}$ & $(0.05-0.28)$ & & & \\
\hline \multicolumn{6}{|l|}{ Gender } \\
\hline \multicolumn{6}{|l|}{ Illness severity } \\
\hline \multicolumn{6}{|c|}{ Predicting WHO overall QoL rating } \\
\hline Overall model & & & $5.18^{* * * *}$ & 0.13 & 0.10 \\
\hline \multicolumn{6}{|l|}{$\mathrm{TAC} / \mathrm{h}$} \\
\hline Q2 & $0.56^{* * *}$ & $(0.20-0.92)$ & & & \\
\hline Q3 & $0.35^{*}$ & $(-0.01-0.71)$ & & & \\
\hline Q4 & 0.22 & $(-0.14-0.59)$ & & & \\
\hline \multicolumn{6}{|l|}{ Gender } \\
\hline \multicolumn{6}{|l|}{ Illness severity } \\
\hline \multicolumn{6}{|c|}{ Predicting WHO health satisfaction rating } \\
\hline Overall model & & & $2.74^{* * *}$ & 0.19 & 0.12 \\
\hline \multicolumn{6}{|l|}{$\mathrm{TAC} / \mathrm{h}$} \\
\hline Q2 & $0.48^{* *}$ & $(0.01-0.95)$ & & & \\
\hline Q3 & 0.41 & $(-0.08-0.90)$ & & & \\
\hline Q4 & $0.50^{*}$ & $(-0.02-1.01)$ & & & \\
\hline \multicolumn{6}{|l|}{$\mathrm{Age}^{\mathrm{a}}$} \\
\hline \multicolumn{6}{|l|}{ Diagnosis } \\
\hline \multicolumn{6}{|l|}{ Illness severity ${ }^{a}$} \\
\hline \multicolumn{6}{|l|}{ Antidepressants } \\
\hline \multicolumn{6}{|c|}{ Predicting WHO physical QoL domain } \\
\hline Overall model & & & $3.72^{* * * *}$ & 0.24 & 0.17 \\
\hline \multicolumn{6}{|l|}{$\mathrm{TAC} / \mathrm{h}$} \\
\hline Q2 & $1.18^{* *}$ & $(0.10-2.26)$ & & & \\
\hline Q3 & $1.66^{* * *}$ & $(0.54-2.79)$ & & & \\
\hline Q4 & $1.50^{* *}$ & $(0.31-2.69)$ & & & \\
\hline \multicolumn{6}{|l|}{$\mathrm{Age}^{\mathrm{a}}$} \\
\hline \multicolumn{6}{|l|}{ Gender } \\
\hline \multicolumn{6}{|l|}{ Diagnosis } \\
\hline \multicolumn{6}{|l|}{ IIIness severity ${ }^{a}$} \\
\hline \multicolumn{6}{|c|}{ Predicting WHO psychological QoL domain } \\
\hline Overall model & & & $3.85^{* * * *}$ & 0.23 & 0.17 \\
\hline \multicolumn{6}{|l|}{$\mathrm{TAC} / \mathrm{h}$} \\
\hline Q2 & $1.09 *$ & $(-0.16-2.35)$ & & & \\
\hline Q3 & 0.90 & $(-0.39-2.20)$ & & & \\
\hline Q4 & 0.30 & $(-1.07-1.68)$ & & & \\
\hline
\end{tabular}

Table 4 Multiple regression models with significant predictors of quality of life $(p<0.10)$, using backward-selection (Continued) Age

Gender

Diagnosis

Illness severity

Use of antipsychotics

Use of antidepressants

Predicting WHO social QoL domain

Overall model

$\mathbf{2 . 3 3 ^ { * * * }} \quad 0.14 \quad 0.08$

$\mathrm{TAC} / \mathrm{h}$

$\begin{array}{lll}\text { Q2 } & \mathbf{1 . 4 9 * *}^{* *} & (0.27-2.72) \\ \text { Q3 } & \mathbf{1 . 1 9 *}^{*} & (-0.03-2.42) \\ \text { Q4 } & 0.97 & (-0.30-2.23)\end{array}$

Years of hospitalization

Diagnosis

Illness severity ${ }^{a}$

Use of antidepressants

Significant results shown in bold. TAC/ $\mathrm{h}=$ average Total Activity Counts per hour; $\mathrm{Q}=$ Quartile $(n=46)$

${ }^{*} p<0.10$. ${ }^{* *} p<0.05$. ${ }^{* * *} p<0.01$. ${ }^{* *} p<0.001$

an quartiles

\section{Attitude and self-efficacy and physical activity}

Table 3 shows the associations between attitude and self-efficacy and PA, reflected in regression coefficients for the particular associations and $F$-values for the models as a whole. After correction, there were no significant associations. In parallel, attitude and selfefficacy were not significant predictors of PA in multiple regression. Of all patient and disease characteristics, only age was a significant predictor $(F=38.66, p<0.001$, $\left.R_{A d j}^{2}=0.29\right)$.

\section{Discussion}

This study clearly showed that (A) PA was positively associated with QoL and a significant predictor of overall, physical, psychological and social QoL, and (B) there was no association between attitude and self-efficacy and PA, contrary to what we expected. These findings are summarized in Fig. 2.

\section{Associations with QoL}

The positive association with QoL needs to be discussed in more detail, as for overall, psychological and social QoL, relationships with PA were strongest for the patients classified in the second quartile. QoL of the most active patients was not significantly different from the QoL of the least active patients (reference group). As there were no big differences in daily programs during the week, weekend activities and approaching patients between wards, it is unlikely that this has affected 


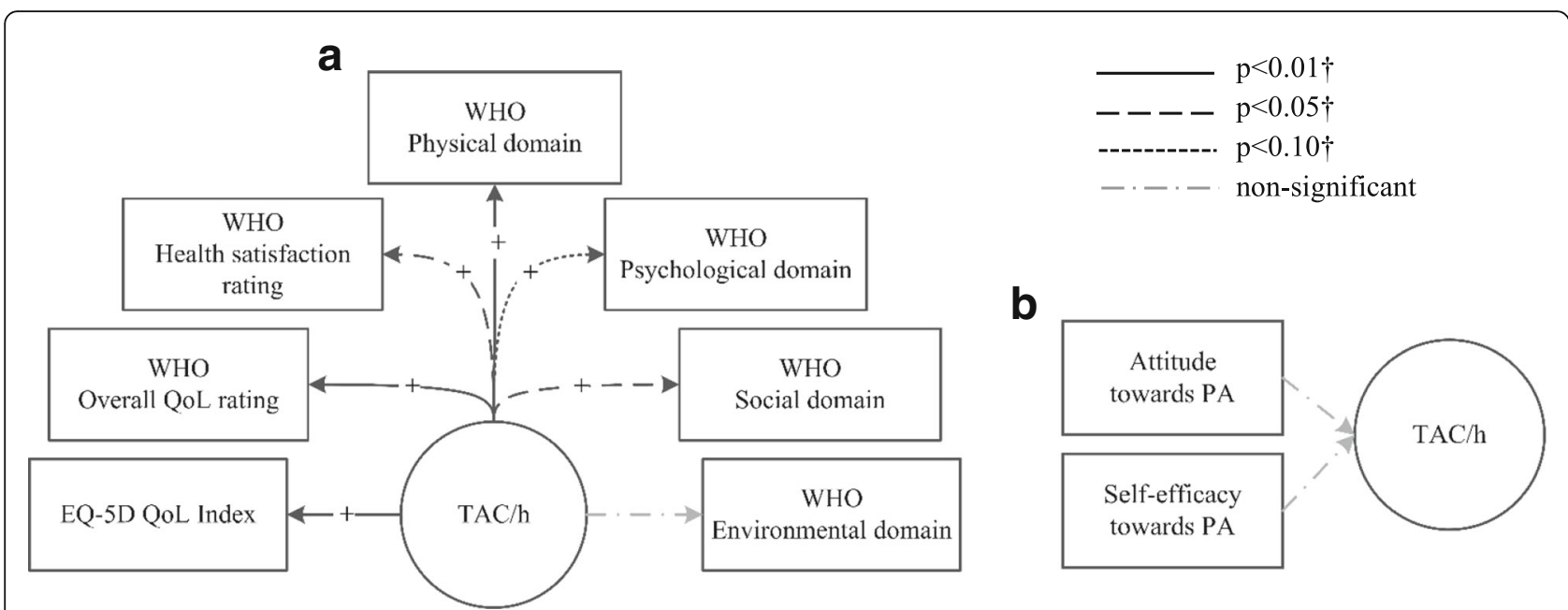

Fig. 2 Summary of the relationships found, controlled for patient and disease characteristics ${ }^{*}$.(a) between physical activity and quality of life. (b) between attitude/self-efficacy and physical activity. TAC/h = average Total Activity Counts per hour; QoL = Quality of Life; EQ5D = EuroQol-5D; $\mathrm{WHO}=$ World Health Organisation. * corrected for any added value to the prediction by gender, age, diagnosis, years of hospitalization, illness severity and use of antipsychotics and antidepressantstFor at least one of the quartiles of TAC/h.

results. Restlessness (caused by e.g. akathisia, which is well-known in this population [40], anxiety or agitated depression) could h'owever be a reason for high activity scores, while having a QoL below average. Nevertheless, adding presence of akathisia (which was available in the database and diagnosed by using the St. Hans Rating Scale [41]) to the models did not change the shape of the relations. Despite that an anxiety disorder was diagnosed only once and a diagnosis of agitated depression is also rare in this population, anxious and agitated feelings are common within psychiatric patients. Especially these feelings can be reflected in perceived psychological and social QoL, which may have been more common in patients with relatively high PA scores within the current study. However, it seems that relevant improvement in QoL can be achieved by activating the most sedentary patients to do/perform more light intensity PA. Intervention studies are needed to analyse such possible causal relationships. Noteworthy are the relatively low levels of explained variance of the models of the significant predictors $(8 \%-17 \%)$. This reflects the complexity of QoL, whereby - apart from patient and disease characteristics and PA - many more factors may play a role. In the QoL analysis, PA was not related to environmental QoL, in both association and prediction models. Years of hospitalization, illness severity and use of antipsychotics were the only significant predictors of environmental QoL. This could be a plausible finding for this population, since the hospitalized setting is a regulated environment itself, which is strongly related to one's pathology and hardly affected by the individual level of physical activity.
These findings show only limited agreement with earlier cross-sectional research on the relationship between PA and QoL in inpatients with SMI. Two studies showed self-reported PA to be (positively) associated only with physical QoL $[42,43]$, while two others found no significant associations with any QoL variable $[8,18]$. These differences may have to do with the power in these studies ( $N=18$ to 60$)$ and the use of self-reports instead of objective measurement of PA.

It is important to perform research in specific SMI groups such as long-term hospitalized patients. Namely, the WHO QoL domain scores were on average 1.5 points higher compared to Dutch psychiatric outpatients and (just) 1.5 points lower than the general Dutch population (on a scale from 4 to 20) [44]. Because the QoL is not as low as we sometimes may assume in clinical practice and the non-linear relationships we found, the question is to what extend more PA can positively influence QoL in this hospitalized population. Current data suggests that slight increases in PA may be enough to improve QoL.

\section{Attitude/self-efficacy and physical activity}

Results showed that SMI inpatients who have a positive attitude towards being physically active and feel able to do so, are not more active than SMI inpatients with a less positive attitude and lower self-efficacy. This might play a role in difficulties activating patients in clinical practice, taking into account that attempts to activate people often involve increasing attitude (e.g. telling them the importance and advantages of PA) and supporting self-efficacy (e.g. by facilitating them with home-trainers at the ward). A previous study showed similar results for 
self-efficacy, finding no association with exercise attendance in outpatients with SMI [45]. The idea that having a positive attitude and high self-efficacy towards PA not necessarily leads to increased PA, is described as the intention-behaviour gap [46]. In this population, a possible explanation for this gap could be a lack of competences to plan the actual activity, due to poor skills in cognitive abilities and systematic thinking [20,21]. Also, based on clinical practice, other attitudes may play a role that compete with healthy behaviour (e.g. if a patient intended to take a walk but ends up with a fellow patient to smoke a cigarette). Nevertheless, although these factors may explain the lack of a relationship between attitude and self-efficacy and PA, this finding guides the way in which we should activate this population. Implementation intentions whereby a person plans when, where and how to act in an if-then format [47] are assumed to improve the translation of one's intention to actual behaviour. However, due to the planning deficits [21], this could be less applicable in this population and a more intensive and guided approach might help to overcome this gap. Support by positive staff attitudes, staff participation (modelling) and peer support are determined as essential factors to affect ones' behaviour to achieve a maximum result with a lifestyle intervention in patients with SMI [48]. Recent systematic reviews on this subject encourage structural physical activities integrated in a multidisciplinary treatment $[6,13,49]$. Moreover, provided that the obesogenic environment will be changed using such an activating strategy, especially inpatient healthcare offers a lot of opportunities. The inpatient setting has the abilities to structurally activate patients to engage in PA and pay attention to the development of habits they can maintain when discharged from the hospital [49].

\section{Strengths and limitations}

So far, little is known about the level of PA of long-term hospitalized patients with SMI. The main strength of the present study is the use of objective measurement of PA in a relatively large group of long-term hospitalized patients with SMI [9] and involving modifiable psychological determinants. This leads to more reliable conclusions, independent of patient and disease characteristics. Accelerometer data are more reliable than self-reports due to psychopathology and impaired cognitive abilities of patients [50] and better registration of the lower spectrum of PA intensity [51]. Besides, by measuring PA in daily clinical practice and by involving modifiable psychological determinants such as attitude and selfefficacy, results are very relevant for clinical practice. Especially, research towards specific groups can contribute to better treatment, such as in long-term hospitalized population with SMI. Findings, such as the QoL scores compared to outpatients and non-linear distributions, show us that patients with SMI in different settings also differ in relationships between PA and QoL and therefore need a different approach.

The cross-sectional design of the present study does not allow the drawing of any conclusions about causality of the relationships. Another limitation is that there is no international consensus on how to set up and process accelerometer data. Besides, validated instruments to assess attitude and self-efficacy are not available in this population, because so far little research on this topic has been done in long-term hospitalized patients with SMI. The self-efficacy questionnaire was slightly adjusted and translated to Dutch by people with excellent command of English, but we did not perform an extensive back and forth translation-procedure. However, as shown in the method section, internal consistencies of the questionnaires were high. Moreover, the levels of explained variance of the models confirm the complex constructs of QoL, in which many individual aspects may play a role. Furthermore, in step-wise regression choices of elimination are based on the current data-set, which means that this procedure possibly reduced generalizability of the results. However, in our opinion this was the best way to achieve the maximum power of models to estimate and predict the relationships as accurately as possible, taking our sample-size into account.

We encourage further research on this topic within hospitalized SMI patients, especially regarding the nonlinear relationship between $\mathrm{TAC} / \mathrm{h}$ and QoL. For example, it would be very relevant for clinical practice to know whether there is a causal relationship between high levels of PA and lower QoL. If this is the case, it must be taken into account in future interventions aiming to improve the poor health status of this population by increasing PA. For such interventions, the lack of association between attitude and self-efficacy and PA suggests the need of a more intensive and guided approach. Therefore, we think that long-term hospitalized patients with SMI will benefit from an integrated, multidisciplinary and peer supported approach focusing on a shift from sedentary behaviour to light intensity PA.

\section{Conclusions}

In summary, the current study showed a positive relationship between PA and QoL, especially for patients in the lower spectrum of PA. Although no causal relationship can be drawn, the data suggests that in long-term hospitalized patients with SMI slight increases in PA may be enough to improve QoL. The lack of association between attitude and self-efficacy and PA suggests the need of a more intensive and guided approach. We encourage further (longitudinal) research to obtain more accurate insights on this topic, which remains priority in this population. 


\section{Abbreviations}

EQ-5D : EuroQol five-dimension questionnaire; LOESS: Locally Estimated Scatterplot Smoothing; LPA: Light Physical Activity; MVPA: Moderate to Vigorous Physical Activity; PA: Physical Activity; Q: Quartile; QoL: Quality of Life; SB: Sedentary Behaviour; SMI: Severe Mental IIIness; TAC/h: average Total Activity Counts per hour; WHOQoL-Bref : World Health Organization Quality of Life questionnaire, brief version.

\section{Acknowledgements}

The authors would like to acknowledge, with thanks, all patients and mental healthcare professionals of GGz Centraal who have made efforts to collect all the data, which formed the basis for this publication.

\section{Funding}

Not applicable.

\section{Availability of data and materials}

The data that support the findings of this study are not publicly available because it is inconsistent with the informed consent. Data are however available from the corresponding author on reasonable request and with permission of GGz Centraal.

\section{Authors' contributions}

JD: study design, collection and analysis of data, drafting and revising the manuscript. FK: study design, drafting and revising the manuscript. DT: study design, supporting collection and analysis of data, revising the manuscript. ABJ and ET1: study design, supporting quality of life, attitude and selfefficacy measurements, revising the manuscript. $\mathrm{MH}$ : revising the manuscript. $A B$ : supporting data analysis, revising the manuscript. ET2: revising the manuscript. $\mid \mathrm{H}$ : study design, supporting accelerometer measurement and data analysis, revising the manuscript. $\mathrm{PH}$ : revising the manuscript. All authors contributed and approved the manuscript.

\section{Ethics approval and consent to participate}

After extensive verbal explanation per ward, taking understandable comments due to the mental illness into account (e.g. fear, suspicion and psychotic thoughts), written informed consent was obtained from all subjects who understood the intent of the study and were willing to participate. All participants were able to decide this by themselves, as reviewed by their attending psychiatrist. The study protocol was approved by the Central Committee on Research Involving Human Subjects (CCMO) before measurements were started.

\section{Consent for publication}

Not applicable.

\section{Competing interests}

The authors declare that they have no competing interests.

\section{Publisher's Note}

Springer Nature remains neutral with regard to jurisdictional claims in published maps and institutional affiliations.

\section{Author details}

'GGz Centraal, Utrechtseweg 266, 3818 EW Amersfoort, The Netherlands. ${ }^{2}$ Faculty of Behavioural, Management and Social sciences, University of Twente, Drienerlolaan 5, 7522 NB Enschede, The Netherlands. ${ }^{3}$ School for Mental Health and Neuroscience Maastricht University, Minderbroedersberg 4-6, 6211 LK Maastricht, The Netherlands. Body@Work, TNO-VU University Medical Centre, Van der Boechorststraat 7, 1081 BT Amsterdam, The Netherlands. ${ }^{5}$ Department of Pharmacoepidemiology and Clinical Pharmacology, Utrecht University, Universiteitsweg 99, 3584 CG Utrecht, The Netherlands. ${ }^{6}$ The Netherlands Organization for applied scientific research TNO, Schipholweg 77-89, 2316 ZL Leiden, The Netherlands. ' $E M G O$ institute for Health and Care Research, Department of Public and Occupational Health, VU University Medical Centre, Van der Boechorststraat 7, 1081 BT Amsterdam, The Netherlands. ${ }^{8}$ Department of Psychiatry, VU University Medical Centre, A.J. Ernststraat 1187, $1081 \mathrm{HL}$ Amsterdam, The Netherlands.
Received: 27 February 2017 Accepted: 14 August 2017

Published online: 18 August 2017

\section{References}

1. Vancampfort D, Stubbs B, Mitchell AJ, De Hert M, Wampers M, Ward PB, Rosenbaum S, Correll CU. Risk of metabolic syndrome and its components in people with schizophrenia and related psychotic disorders, bipolar disorder and major depressive disorder: a systematic review and metaanalysis. World Psychiatry. 2015;14(3):339-47.

2. Walker ER, McGee RE, Druss BG. Mortality in mental disorders and global disease burden implications a systematic review and meta-analysis. Jama Psychiatry. 2015;72(4):334-41.

3. Laursen TM, Wahlbeck K, Hallgren J, Westman J, Osby U, Alinaghizadeh H, Gissler M, Nordentoft M. Life Expectancy and Death by Diseases of the Circulatory System in Patients with Bipolar Disorder or Schizophrenia in the Nordic Countries. PLoS One. 2013;8(6).

4. Dauwan M, Begemann MJH, Heringa SM, Sommer IE. Exercise improves clinical symptoms, quality of life, global functioning, and depression in schizophrenia: a systematic review and meta-analysis. Schizophr Bull. 2016; 42(3):588-99.

5. Rosenbaum S, Tiedemann A, Sherrington C, Curtis J, Ward PB. Physical activity interventions for people with mental illness: a systematic review and meta-analysis. J Clin Psychiatry. 2014;75(9):964-74.

6. Vera-Garcia E, Mayoral-Cleries F, Vancampfort D, Stubbs B, Cuesta-Vargas Al. A systematic review of the benefits of physical therapy within a multidisciplinary care approach for people with schizophrenia: an update. Psychiatry Res. 2015;229(3):828-39.

7. Stubbs B, Williams JE, Gaughran F, Craig T. How sedentary are people with psychosis? A systematic review and meta-analysis. Schizophr Res. 2016; 171(1-3):103-9.

8. Vancampfort D, Guelinckx H, Probst M, Stubbs B, Rosenbaum S, Ward PB, De Hert M. Health-related quality of life and aerobic fitness in people with schizophrenia. Int J Ment Health Nurs. 2015:24(5):394-402.

9. Kruisdijk F, Deenik J, Tenback D, Tak E, Beekman A-J, van Harten P, HopmanRock M, Hendriksen I. Accelerometer-measured sedentary behaviour and physical activity of inpatients with severe mental illness. Psychiatry Res. 2017;254:67-74.

10. Awad AG, Voruganti LNP. Measuring quality of life in patients with schizophrenia. PharmacoEconomics. 2012:30(3):183-95.

11. Chen LJ, Steptoe A, Chung MS, Ku PW. Association between actigraphyderived physical activity and cognitive performance in patients with schizophrenia. Psychol Med. 2016;46(11):2375-84.

12. Stubbs B, Ku PW, Chung MS, Chen LJ. Relationship Between Objectively Measured Sedentary Behavior and Cognitive Performance in Patients With Schizophrenia Vs Controls. Schizophr Bull. 2016; doi: https://doi.org/10.1093/ schbul/sbw126.

13. Farholm A, Sørensen M. Motivation for physical activity and exercise in severe mental illness: a systematic review of intervention studies. Int J Ment Health Nurs. 2016;25(3):194-205.

14. Ringen PA, Engh JA, Birkenaes AB, Dieset I, Andreassen OA. Increased mortality in schizophrenia due to cardiovascular disease - a non-systematic review of epidemiology, possible causes, and interventions. Frontiers Psychiatry 2014;5:137-137.

15. Faulkner GE, Gorczynski PF, Cohn TA. Psychiatric illness and obesity: recognizing the "obesogenic" nature of an inpatient psychiatric setting. Psychiatr Serv. 2009;60(4):538-41.

16. Ajzen I, Madden TJ. Prediction of goal-directed behavior: attitudes, intentions, and perceived behavioral control. J Exp Soc Psychol. 1986; 22(5):453-74

17. Fishbein $\mathrm{M}$, Cappella JN. The role of theory in developing effective health communications. Aust J Commun. 2006:56:S1-S17.

18. Bonsaksen T, Lerdal A. Relationships between physical activity, symptoms and quality of life among inpatients with severe mental illness. Br J Occup Ther. 2012;75(2):69-75

19. Brüne M. "theory of mind" in schizophrenia: a review of the literature Schizophr Bull. 2005;31(1):21-42.

20. Dam J. Insight in schizophrenia: a review. Nordic J Psychiatry. 2006:60(2):114-20

21. Holt DV, Wolf J, Funke J, Weisbrod M, Kaiser S. Planning impairments in schizophrenia: specificity, task independence and functional relevance. Schizophr Res. 2013;149(1-3):174-9. 
22. Nolen WA. Globale Klinische Beoordeling (clinical global impression: CGI). Groningen: UMC; 1990.

23. Jarrett $H$, Fitzgerald L, Routen AC. Interinstrument reliability of the ActiGraph GT3X+ambulatory activity monitor during free-living conditions in adults. J Phys Act Health. 2015;12(3):382-7.

24. Gatti AA, Stratford PW, Brenneman EC, Maly MR. GT3X+ accelerometer placement affects the reliability of step-counts measured during running and pedal-revolution counts measured during bicycling. J Sports Sci. 2015;34(12):1-8.

25. McMinn D, Acharya R, Rowe DA, Gray SRA, Allan JLA. Measuring activity energy expenditure: accuracy of the GT3X+ and actiheart monitors. Int J Exerc Sci. 2013;3:217-29.

26. Lamers LM, McDonnell J, Stalmeier PFM, Krabbe PFM, Busschbach JJV. The Dutch tariff: results and arguments for an effective design for national EQ5D valuation studies. Health Econ. 2006;15(10):1121-32.

27. Prieto L, Sacristan JA, Hormaechea JA, Casado A, Badia X, Gomez JC. Psychometric validation of a generic health-related quality of life measure (EQ-5D) in a sample of schizophrenic patients. Curr Med Res Opin. 2004; 20(6):827-35.

28. Brooks R, De Charro F. EuroQol: the current state of play. Health Policy. 1996;37(1):53-72.

29. Breek JC, De Vries J, Van Heck GL, Van Berge Henegouwen DP, Hamming JF. Assessment of disease impact in patients with intermittent claudication: discrepancy between health status and quality of life. J Vasc Surg. 2005. 41(3):443-50.

30. Karow A, Wittmann L, Schottle D, Schafer I, Lambert M. The assessment of quality of life in clinical practice in patients with schizophrenia. Dialogues Clin Neurosci. 2014;16(2):185-95.

31. Mas-Expósito L, Amador-Campos JA, Gómez-Benito J, Lalucat-Jo L. The World Health Organization quality of life scale brief version: a validation study in patients with schizophrenia. Qual Life Res. 2011;20(7):1079-89.

32. Trompenaars FJ, Masthoff ED, Van Heck GL, Hodiamont PP, De Vries J. Content validity, construct validity, and reliability of the WHOQOL-Bref in a population of Dutch adult psychiatric outpatients. Qual Life Res. 2005;14(1):151-60.

33. Kendzierski D, DeCarlo KJ. Physical activity enjoyment scale: two validation studies. J Sport Exerc Psychol. 1991;13(1):50-64.

34. van Sluijs EMF, van Poppel MNM, Twisk JWR, Brug J, van Mechelen W. The positive effect on determinants of physical activity of a tailored, general practice-based physical activity intervention. Health Educ Res. 2005;20(3):345-56.

35. Benisovich SV, Rossi JS, Norman GJ, Nigg CR. Development of a multidimensional measure of exercise self-efficacy. Ann Behav Med. 1998;20(S190).

36. Jacoby WG. Loess: a nonparametric, graphical tool for depicting relationships between variables. Elect Stud. 2000;19(4):577-613.

37. Carr LJ, Mahar MT. Accuracy of intensity and inclinometer output of three activity monitors for identification of sedentary behavior and light-intensity activity. J Obes. 2012;2012 doi:https://doi.org/10.1155/2012/460271.

38. Kozey-Keadle S, Libertine A, Lyden K, Staudenmayer J, Freedson PS. Validation of wearable monitors for assessing sedentary behavior. Med Sci Sports Exerc. 2011;43(8):1561-7

39. Santos-Lozano A, Santín-Medeiros F, Cardon G, Torres-Luque G, Bailón R Bergmeir C, Ruiz JR, Lucia A, Garatachea N. Actigraph GT3X: validation and determination of physical activity intensity cut points. Int J Sports Med. 2013;34(11):975-82.

40. van Harten PN, Bakker PR, Mentzel CL, Tijssen MA, Tenback DE. Movement Disorders and Psychosis, a Complex Marriage. Frontiers in Psychiatry. 2015; 5(190); doi: https://doi.org/10.3389/fpsyt.2014.00190.

41. Gerlach J, Korsgaard S, Clemmesen P, Lauersen AML, Magelund G, Noring U, Povlsen UJ, Bech P, Casey DE. The St. Hans rating scale for extrapyramidal syndromes: reliability and validity. Acta Psychiatr Scand. 1993;87(4):244-52

42. Pesek MB, Mihoci J, Medved K, Šolinc NP. Long term groups of patients with psychosis: physical activity and medical treatment. Psychiatr Danub. 2011:23:149-54

43. Vancampfort D, Probst M, Scheewe T, Maurissen K, Sweers K, Knapen J, De Hert M. Lack of physical activity during leisure time contributes to an impaired health related quality of life in patients with schizophrenia. Schizophr Res. 2011;129(2-3):122-7.

44. Masthoff ED, Trompenaars FJ, Van Heck GL, Hodiamont PP, De Vries J. Quality of life and psychopathology: investigations into their relationship. Aust N Z J Psychiatry. 2006;40(4):333-40.
45. Daumit GL, Dalcin AT, Jerome GJ, Young DR, Charleston J, Crum RM, Anthony C, Hayes JH, McCarron PB, Khaykin E, et al. A behavioral weight loss intervention for persons with serious mental illness in psychiatric rehabilitation centers. Int J Obes. 2011;35(8):1114-23.

46. Sniehotta FF, Schwarzer R, Scholz U, Schüz B. Action planning and coping planning for long-term lifestyle change: theory and assessment. Eur J Soc Psychol. 2005;35(4):565-76.

47. Gollwitzer PM. Implementation intentions: strong effects of simple plans. Am Psychol. 1999;54(7):493-503.

48. Roberts SH, Bailey JE. Incentives and barriers to lifestyle interventions for people with severe mental illness: a narrative synthesis of quantitative, qualitative and mixed methods studies. J Adv Nurs. 2011;67(4):690-708.

49. Stanton R, Happell B. Exercise for mental illness: a systematic review of inpatient studies. Int J Ment Health Nurs. 2014;23(3):232-42.

50. Aleman A, Hijman R, De Haan EHF, Kahn RS. Memory impairment in schizophrenia: a meta-analysis. Am J Psychiatry. 1999;156(9):1358-66.

51. Bassett DR, Troiano RP, McClain JJ, Wolff DL. Accelerometer-based physical activity: Total volume per day and standardized measures. Med Sci Sports Exerc. 2015;47(4):833-8.

\section{Submit your next manuscript to BioMed Central and we will help you at every step:}

- We accept pre-submission inquiries

- Our selector tool helps you to find the most relevant journal

- We provide round the clock customer support

- Convenient online submission

- Thorough peer review

- Inclusion in PubMed and all major indexing services

- Maximum visibility for your research

Submit your manuscript at www.biomedcentral.com/submit

) Biomed Central 